\title{
Simulation Model for Minimal Invasive Refurbishment Approaches Through Prefabricated Multifunctional Radiant Heating Façade Elements
}

\author{
Michael Bayer, Markus Karnutsch, Michael Grobbauer, Matthias Gnigler, Markus Leeb \\ Salzburg University of Applied Sciences, Puch/Salzburg, Austria
}

\begin{abstract}
This paper describes an approach for validating and calibrating a digital twin of a prefabricated multifunctional radiant heating façade element. In December 2017, a prototype equipped with sensors able to log surface and layer temperature (on the inside and outside surface and within the construction layers), relative humidity as well as vertical global irradiation was mounted to the existing brickwork wall. The measurement interval was set to one minute. Two different control strategies for a minimal invasive radiant heating systems are compared in regard to energy efficiency and the deviation of the room temperature from a defined set point by thermal simulation. The validation is executed through alignments of simulation results and measured data by implementing measured boundary conditions. Results concerning the minimal inlet flow temperature, the control strategy and the thermal behavior can be multiplied and utilized for the refurbishment process of the whole building.
\end{abstract}

\section{Introduction}

The refurbishment of post-war buildings all over Europe is facing different kinds of challenges in order to adapt them for the future. Most important is the energy demand of buildings, which sums up to approximately $40 \%$ of the global energy demand - a catalyst consequently and predominantly addressed by many concepts of urban district modernization. (Bindra and Scanlon, 2010). Based on the ageing structure of the buildings and due to the missing/poor thermal insulation as well as heterogenic energy supply systems in such housings, the heating energy demand can be substantially improved.

A demonstration site in the city of Hallein/Austria with high traffic congestion and a uniform, overaged building stock from the 1950s serves as an example for similar settlement structures in Europe. In Austria $11 \%$ (Statistics Austria, 2011) and in Europe $18 \%$ (Birchall et al. 2016) of the building stock are multi-family buildings, erected during the same time period as the reference building. A minimal invasive refurbishment approach (i.e. multifunctional radiant heating façade and sound absorption for the building surroundings) should guarantee little disturbance of the tenants during renovation and a life-cycle extension of the stock.

The aim of this paper is to present the validation and calibration of a digital twin for a prefabricated façade and a comparison of possible control strategies with data collected during the monitoring phase between Feb. 2018 and April 2018. For this purpose, a simulation model of the façade prototype and the heated room is created with the dynamic thermal simulation software IDA ICE 4.8.

The prototype (figure 1) was installed on the demonstration object in December 2017 and was designed, planned and implemented together with the cooperation partners. It combines the functions of heating, thermal insulation and sound absorption in one prefabricated element with a glue-free cross-laminated timber wall on which heating pipes are pre-mounted. The outside layers (from inside to outside) consist of thermal insulation, rear ventilation and sound absorbing woodcement panels. This multifunctional façade element is mounted on the outside of the existing wall with some distance in order to compensate the unevenness of the wall. Afterwards, the gap is filled with low-viscosity cement mortar to achieve a stable thermal contact between piping and the existing brickwork wall.

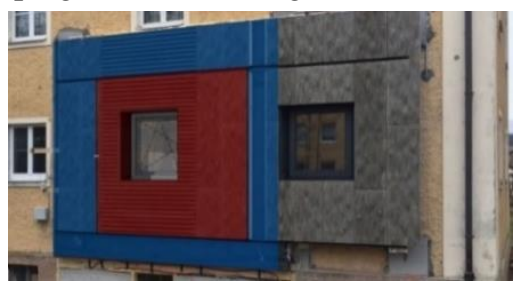

Figure 1: Mounted prototype.

\section{Building data}

The specific heating demand of the unrefurbished building is $136.2 \mathrm{kWh} / \mathrm{m}^{2} \mathrm{a}$. The outer wall consists of solid brickwork with lime mortar $(0.38 \mathrm{~m})$. On the inside and outside, layers of lime plaster add $0.05 \mathrm{~m}$ of material leading to a total thickness of $0.43 \mathrm{~m}$. As part of the renovation work, the interior lime plaster was removed, which results in a $0.41 \mathrm{~m}$ thick wall at the time of refurbishment. The apartment relevant for the measurement is located on the ground floor of the building. In figure 2 the red line marks the borders of the apartment in which the measurement room (green) is situated.

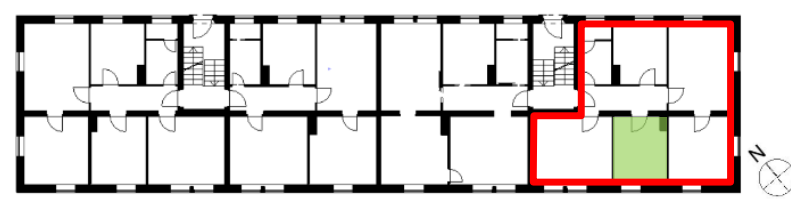

Figure 2: Location of the apartment. 
This room was selected because of the fact that the surrounding rooms can be heated to a target temperature of $22{ }^{\circ} \mathrm{C}$ - as desired in the measurement room - by means of a central heating system. It is also a critical room within the building in terms of the low ratio (1:1.79) between the façade heating surface and the size of the room. Consequently, the performance of this room can significantly exemplify the overall heating performance of the radiant heating system and subsequently the obtainable room and surface temperatures as well as material humidity for the entire building.

\section{Prototype}

The prototype was prefabricated as an element and fastened to the existing brickwork wall on site using steel brackets.

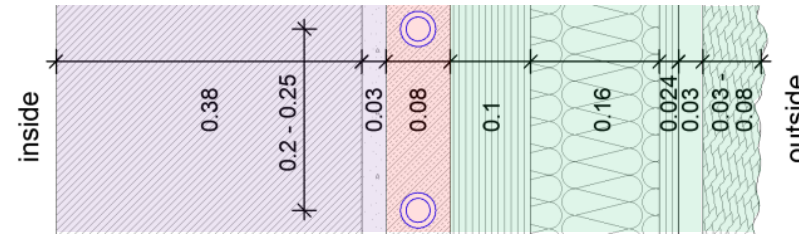

Figure 3: Layer structure of the existing wall (purple) and the mounted prototype (green) including the activated layer of low-viscosity cement mortar including the pre-mounted heating pipes (red).

Figure 3 shows the existing brickwork wall with lime cement plaster $(0.41 \mathrm{~m})$, the layer of low-viscosity cement mortar $(0.08 \mathrm{~m})$, and the prototype consisting of five layers, namely glue-free cross laminated dowelled timber - CLT - $(0.1 \mathrm{~m})$, blown in cellulose insulation $(0.16 \mathrm{~m})$, wood formwork $(0.024 \mathrm{~m})$ serving as a box for the insulation, battens with air gap $(0.03 \mathrm{~m})$ for rear ventilation and sound-absorbing cement bound particle panels with inhomogeneous surface structure provided by the manufacturer Velox (0.05-0.08 m).

The pre-mounted heating circuits (on the wooden module) for activating the brickwork wall are located in the $0.08 \mathrm{~m}$ gap between existing wall and prototype, filled with the low-viscosity cement mortar. The heating pipes (KeKelit KELOX multi-layer composite pipes) have a wall thickness of $0.00225 \mathrm{~m}$ and a total diameter of $0.02 \mathrm{~m}$. The center distance between the heating pipes varies between $0.2 \mathrm{~m}$ and $0.25 \mathrm{~m}$.

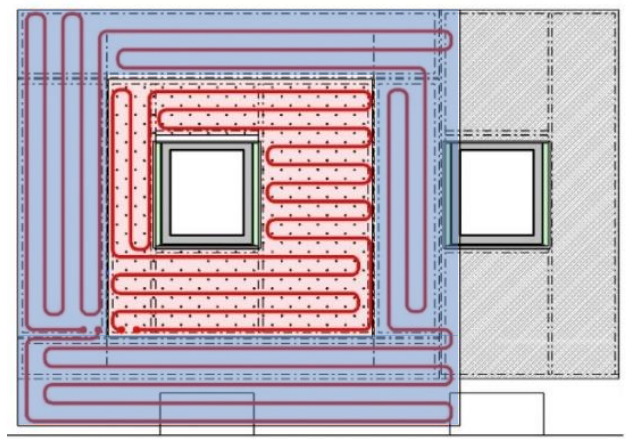

Figure 4: Heating circuits prototype.

Figure 4 shows that two separate heating circuits were installed. Heating circuit one (red) covers the exterior wall of the measurement room on an area of $5.97 \mathrm{~m}^{2}$. Heating circuit two (blue) covers an area of $11.24 \mathrm{~m}^{2}$ and was installed surrounding heating circuit one counteracting thermal bridge losses and serving as edge heating. Without it, heating circuit one would border to nonactivated low-viscosity cement mortar, leading to additional heat transmission losses falsifying the measurement result. This approach ensures realistic and comparable conditions.

An area of $6.18 \mathrm{~m}^{2}$ of the prototype was not activated and is used for other research purposes.

Table 1: Physical properties of the refurbished wall.

\begin{tabular}{|l|c|c|c|c|}
\hline $\begin{array}{l}\text { layer } \\
\text { (inside - outside) }\end{array}$ & $\begin{array}{c}\mathbf{d} \\
\mathrm{m}\end{array}$ & $\begin{array}{c}\boldsymbol{\lambda} \\
\mathrm{W} / \mathrm{mK}\end{array}$ & $\begin{array}{c}\mathbf{\rho} \\
\mathrm{kg} / \mathrm{m}^{3}\end{array}$ & $\begin{array}{c}\mathbf{c}_{\mathbf{p}} \\
\mathrm{J} / \mathrm{kgK}\end{array}$ \\
\hline brickwork & 0.38 & $0.83^{*}$ & 1500 & 920 \\
\hline lime-cement plaster & 0.03 & 0.7 & 1600 & 1130 \\
\hline cement mortar & 0.08 & $0.5^{*}$ & 1970 & 1000 \\
\hline CLT (glue free) & 0.1 & $0.04^{*}$ & 475 & 1600 \\
\hline cellulose insulation & 0.16 & 0.038 & 54 & 2100 \\
\hline wood formwork & 0.024 & 0.12 & 475 & 1700 \\
\hline façade lining & 0.0006 & 0.22 & 170 & 792 \\
\hline battens with air gap & 0.03 & 0.278 & 1.2 & 1008 \\
\hline sound panels & 0.05 & 0.125 & 750 & 1400 \\
\hline
\end{tabular}

* Discussion of marked values in chapter Validation of the prototype.

The properties shown in Table 1 are either standard values for materials of the existing wall or they derive from datasheets of the components of the prefabricated wooden element. The properties of the cement mortar and the glue-free CLT deviate from standard properties in literature. This is discussed in the chapter Validation of the simulation model.

\section{Methods}

The process of validation in this paper involves a simulation within IDA ICE 4.8 and an iterative based manual calibration. It includes trial and error in order to manually tune model input parameters starting from standard values and measurement data. The modeling process starts with setting up the geometry of the observed zone and the surrounding areas. Validation is done by the assignment of thermal properties of the construction, implementation of measured boundary conditions derived from on-site measurements, definition of control strategies, troubleshooting of errors and trial and error in order to calibrate the model as close as possible to the measured thermal behavior.

\section{On-site measurements}

The core of the data acquisition is the implemented monitoring concept. For the following simulation process, the relevant parameters were measured during the test period. These include:

- Ambient air temperature and humidity

- Solar radiation on the façade surface

- Indoor air temperature of the adjacent rooms

- Detailed ventilation protocol

- Inlet flow temperature of the façade heating element

- Inlet mass flow of the façade heating element

Figure 5 gives an insight into the sensor positioning. The room conditions of the rooms adjacent to the measurement room (highlighted in green) were gathered 
by the use of air quality monitors (air temperature and humidity, $\mathrm{CO}_{2}$-level) installed in the middle of the rooms.

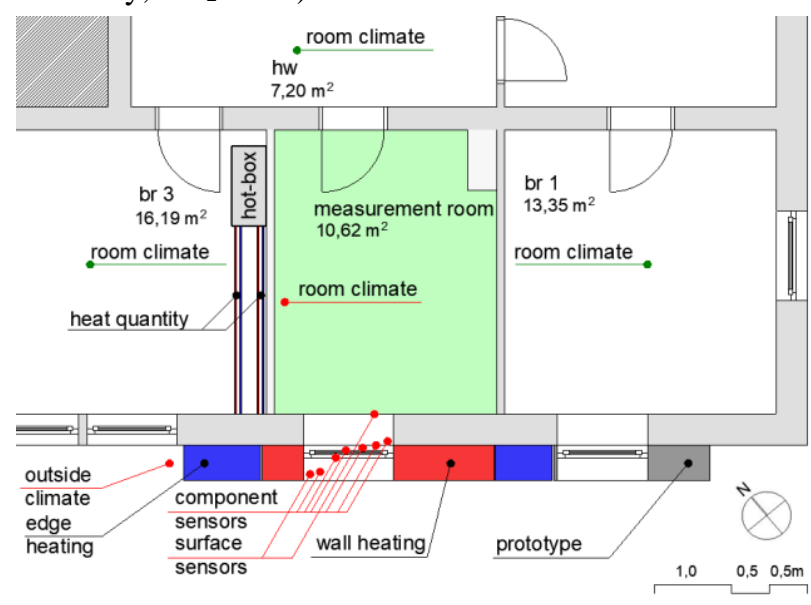

Figure 5: Sensor positioning.

An overview of the sensors and their accuracy is listed below:

\section{- component/outside climate sensors}

$\mathrm{E}+\mathrm{E}$ electronics EE071

Component temperature and humidity

Indoor and outdoor climate (with radiation protection E+E Elektronik HA010502)

Temperature: $\pm 0.5 \%$ to $1 \%$ at $23{ }^{\circ} \mathrm{C}$

range: $-40 \ldots 80{ }^{\circ} \mathrm{C}$

Humidity: $2 \%$ rh to $3 \%$ rh at $90 \ldots 100 \%$ rh

Range: $0 \ldots 100 \%$

\section{- surface sensors}

Thermocon TF14/OF14

Surface temperature inside and outside

Temperature: $\pm 1 \%$ at $21{ }^{\circ} \mathrm{C}$

- heat quantity sensors

Danfoss SonoMeter 30

Heat quantity meter for wall and edge heating circuit Heat quantity: $\pm 4 \%$ at $1.5 \mathrm{~m}^{3} / \mathrm{h}$

Range: $0 \ldots 180{ }^{\circ} \mathrm{C} ; 0.015 \ldots 3 \mathrm{~m}^{3} / \mathrm{h}$

\section{- outside climate: irradiation sensor}

Technical Alternative global radiation (GBS01)

Global radiation: $\pm 5 \%$ additional $\pm 50 \mathrm{~W}$

Range: linear $0 \ldots 1400 \mathrm{~W} / \mathrm{m}^{2}$

\section{- room climate sensors}

AQM air quality monitor G3

Temperature, humidity and $\mathrm{CO}_{2}$ monitoring device

Indoor climate of the surrounding rooms

Temperature: $\pm 1{ }^{\circ} \mathrm{C}$ (range: $0 \ldots 50{ }^{\circ} \mathrm{C}$ )

Humidity: $\pm 0,5 \%$ rh (range: $0 \ldots 100 \%$ rh)

$\mathrm{CO}_{2}: \pm 30$ ppm, $\pm 0,5 \%$ (range: $0 \ldots 5000 \mathrm{ppm}$ )

The component sensors were inserted into the façade through drilled holes and sealed with airtight sealing compound. In addition, an airtight sleeve was put over the sensor to limit the measuring gap. The component sensors measure the humidity and temperature of the resulting microclimate at six points in the façade construction (numbers 2-7 in figure 6) Furthermore, the surface temperatures of the inner and outer surfaces of the thermal envelope were recorded (number 1 and 8 in figure 6).

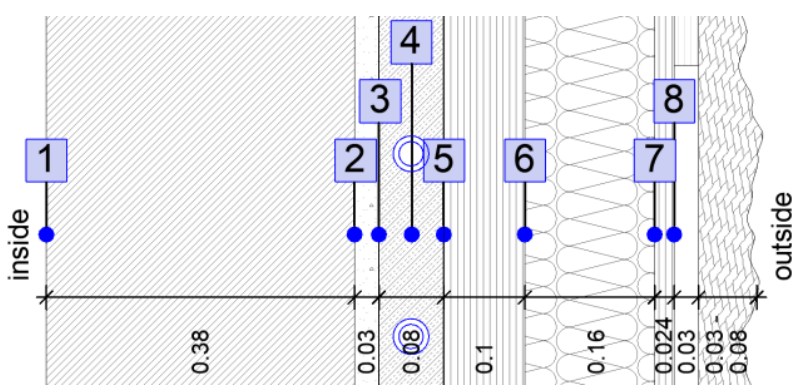

Figure 6: Component sensor positioning.

\section{Control strategy of the heating circuit}

A heating unit (hot-box) was installed (location is displayed in figure 5) for supplying heat to the two heating circuits installed on the prototype. Due to the fact that the heating pipes between the hot-box and the heating circuits are installed without piping insulation, additional heat losses are calculated with a heat transfer coefficient between liquid $\left(35^{\circ} \mathrm{C}\right)$ and ambient $\left(20^{\circ} \mathrm{C}\right)$ of $5.9 \mathrm{~W} / \mathrm{m}^{2} \mathrm{~K}$ for the multi-layer composite pipes.

Both heating circuits were recorded separately with heat quantity counters. The inlet flow temperature was controlled depending on a three hourly mean of the ambient temperature, decreasing linearly from $35^{\circ} \mathrm{C}$ at $15^{\circ} \mathrm{C}$ ambient temperature to $20^{\circ} \mathrm{C}$ at $20^{\circ} \mathrm{C}$ ambient temperature, and an approximately constant volume flow of maximum $0.144 \mathrm{~kg} / \mathrm{s}$. The relatively high flow volume, compared to standard values ranging between $0.016 \mathrm{~kg} / \mathrm{s}$ and $0.083 \mathrm{~kg} / \mathrm{s}$ according to Todorvic et al. (2015), was set in order to achieve a homogenous temperature distribution over the heated surface.

\section{Conditioning of the apartment}

In order to eliminate or minimize the transmission losses to the neighboring rooms, the entire apartment (except for the measurement room) was heated by radiators, connected to the building's central heating system. The apartment was conditioned to a temperature of $21^{\circ} \mathrm{C}$ to $22{ }^{\circ} \mathrm{C}$ in order to achieve almost adiabatic conditions between the measurement room and the neighboring rooms. The apartment located above the tested apartment is inhabited and conditioned. Due to the fact that it was immanent to keep the disturbance of inhabitants at a minimum, it was not possible to measure the temperature of the room above the measurement room. As a result, the simulation was conducted with a temperature variation between $15^{\circ} \mathrm{C}$ and $26^{\circ} \mathrm{C}$, in order to achieve the bandwidth of the possible simulated room conditions of the tested room. The intermediate ceiling of the cellar below was insulated and thus achieves a U-value of $0.26 \mathrm{~W} / \mathrm{m}^{2} \mathrm{~K}$. Heat losses occur due to this ceiling, which have a great influence on the expected heat load of the measurement room. The temperature inside the basement was measured similar to the adjacent rooms.

\section{Calculation of surface temperatures}

Within the environment of IDA ICE 4.8, one detailed zone is defined. Due to numeric issues of the solver, it is not possible to create a room zone which follows a given mean air temperature according to an imported file. Hence the calculated surface temperature of the adjacent walls is 
used for the simulation. The direction of the heat flow, shown in figure 7 , depends on the temperature difference between the measurement room and the adjacent room temperature. For linking them to the simulation environment, calculations to determine the surface temperatures for each time-step are conducted by using the following formulas (1), (2) and (3). (Schmidt et al. (2017)

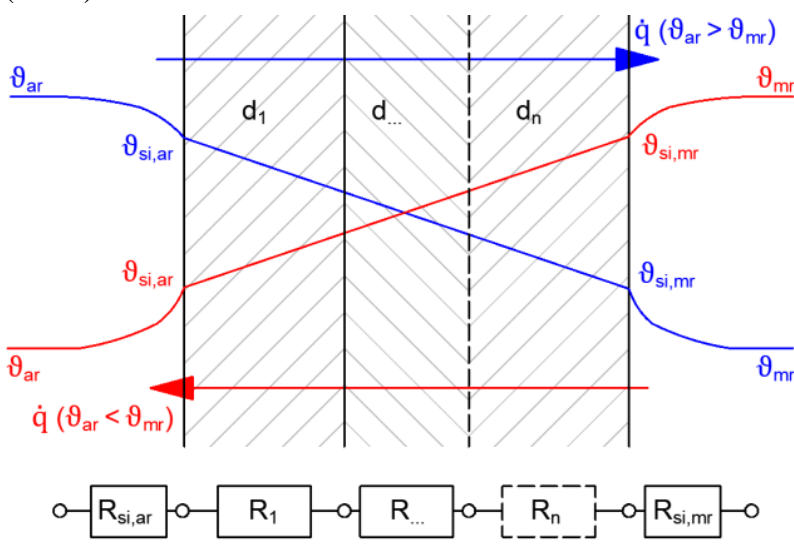

Figure 7: Wall resistance model.

$$
\begin{gathered}
\dot{\mathrm{q}}=\frac{1}{\mathrm{R}_{\mathrm{tot}}} *\left(\vartheta_{\mathrm{mr}}-\vartheta_{\mathrm{ar}}\right) \\
\mathrm{R}_{\mathrm{tot}}=\mathrm{R}_{\mathrm{si}, \mathrm{mr}}+\frac{\mathrm{d}_{1}}{\lambda_{1}}+\frac{\mathrm{d} \ldots}{\lambda_{\ldots}}+\frac{\mathrm{d}_{\mathrm{n}}}{\lambda_{\mathrm{n}}}+\mathrm{R}_{\mathrm{si}, \mathrm{ar}} \\
\vartheta_{\mathrm{SF}, \mathrm{ar}}=\vartheta_{\mathrm{ar}}-\mathrm{R}_{\mathrm{si}, \mathrm{ar}} * \dot{\mathrm{q}}
\end{gathered}
$$

\section{$\dot{\mathrm{q}}$...conductive heat transfer}

$\mathrm{R}_{\text {tot }}$.. resistance to heat flow of wall in total

$\vartheta_{\mathrm{mr}} \ldots$.temperature of measuring room

$\vartheta_{\text {ar }}$..temperature of adjacent room

$\mathrm{R}_{\text {si,mr }} \ldots$ surface resistance to heat flow

$\mathrm{R}_{\mathrm{si}, \mathrm{ar}}$...surface resistance to heat flow

$\vartheta_{\mathrm{SF}, \mathrm{ar}} \ldots$... surface temperature of adjacent room

\section{Ventilation control}

In order to simulate natural ventilation behavior by the residents, the apartment was ventilated naturally twice a day on weekdays during the core time of the measurement (19.02.2018 to 10.03.2018). The calculations for the ventilation duration were carried out in accordance with EN 13465 (EN 13465, 2004), shown in formula (4). The temperature difference between indoor and outdoor air influences the volume flow through the open windows. A single air change per ventilation interval was calculated. Depending on the outside temperatures, the ventilation times were between 200 and 400 seconds.

$$
\mathrm{q}_{\mathrm{v} \text { airing }}=\mathrm{C}_{\mathrm{D}} * \rho * \frac{\mathrm{A}_{\mathrm{W}}}{3} * \sqrt{\frac{\Delta \vartheta^{*} \mathrm{~g} * \mathrm{H}_{\mathrm{WD}}}{\frac{\vartheta_{\text {int }}+\vartheta_{\text {out }}}{2}}}
$$

$\mathrm{q}_{\mathrm{v} \text { airing }}$... airing flow

$C_{D} \ldots$ discharge coefficient of an opening

$\mathrm{A}_{\mathrm{W}} \ldots$ opening area

$\Delta \vartheta \ldots$ temperature difference betw. room and ambient

$\mathrm{H}_{\mathrm{WD}}$... average height from bottom to top of opening $\vartheta_{\text {int }}$...room temperature

$\vartheta_{\text {out }} \ldots$ ambient temperature

\section{Results}

This chapter describes the validation of the simulation model based on measurements, performed on the prototype, inside the measurement room and inside the adjacent building zones. Additionally, the necessary inlet flow temperature of the radiant heating system is given and two control strategies (pulsing and sliding) are compared with each other.

\section{Validation of the simulation model}

A validated model of the prototype forms the basis for further simulations of the entire building. Besides the IDA ICE 4.8 simulation, additional calculations within the simulation environment WUFI Pro 6.2 (simulation program for transient calculation of the coupled heat and moisture transport in components) are conducted. The measured temperature is used in order to determine the thermal conductivity of the individual building materials. Figure 8 shows the wall structure of the WUFI simulation model (camera symbol: monitoring position; light bulb: heat source; tap symbol: moisture source).

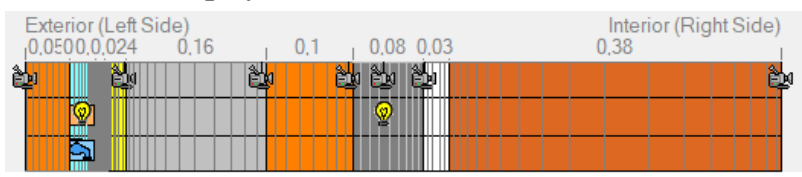

Figure 8: Simulation model WUFI.

A step by step manual parameter modification of the material properties is performed within WUFI Pro 6.2 by comparing boundary layer temperatures with the measured values. The average heating fluid temperature is calculated based on the mean difference between the inlet flow temperature and the return flow temperature. Figure 9 shows the comparison of measured and simulated temperature at predetermined points within the layers of the refurbished wall structure.

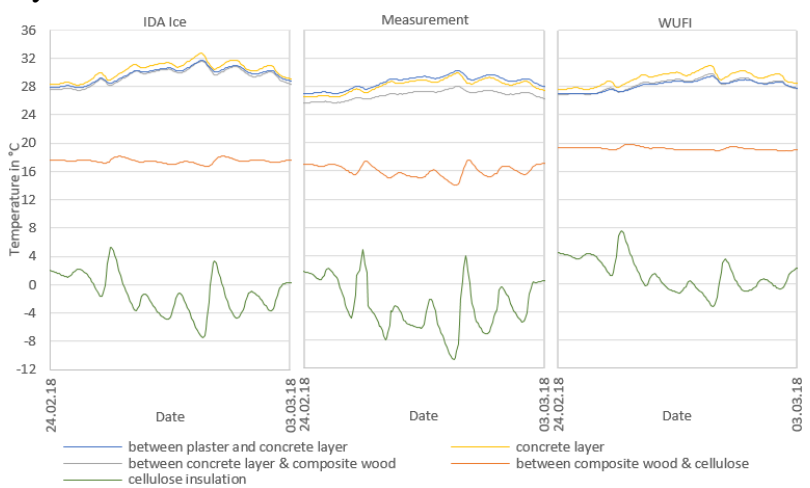

Figure 9: Wall layer temperature.

Relevant deviations from the previously assumed material properties are in detail:

The average difference between measured internal surface temperature and measured room temperature amounts to $0.76 \mathrm{~K}$ and can be reproduced by calculating with a reduced surface resistance to heat flow of $0.066 \mathrm{~m}^{2} \mathrm{~K} / \mathrm{W}$, compared to the standard value of $0.125 \mathrm{~m}^{2} \mathrm{~K} / \mathrm{W}$ (ÖNORM EN ISO 6946, 2018). An 
educated conjecture for this deviation is an inversion of the heat flux due to high temperatures within the activated cement mortar layer.

For the outside surface of the model, the surface transition to heat flow is set to $0.13 \mathrm{~m}^{2} \mathrm{~K} / \mathrm{W}$ (ÖNORM B 8110-7, 2013). The temperature inside the air gap is calculated in a way, that the external surface temperature is in accordance with the measured values.

Within the $0.38 \mathrm{~m}$ thick brickwork layer, an average temperature drop of $3.4 \mathrm{~K}$ occurs. This temperature drop indicates a high thermal conductivity of $0.83 \mathrm{~W} / \mathrm{mK}$, which can be regarded as the upper limit for the thermal conductivity of solid brickwork (ÖNORM B 8110-7, 2013).

In a first approach, a typical value for the thermal conductivity of the activated cement mortar layer of $0.9 \mathrm{~W} / \mathrm{mK}$ is used. Results of the parameter variation show, that the measured temperature within the cement mortar layer can only be reproduced in the simulation using a thermal conductivity of $0.5 \mathrm{~W} / \mathrm{mK}$. This does not indicate that the thermal conductivity of the activated cement mortar layer is not meeting typical specifications, but leads to the assumption, that the thermal resistance of the activated layer is increased due to air inclusions. Those air inclusions are caused by the dwindling and creeping behavior of the mortar itself. After opening and examination of the prototype, it was possible to confirm those air inclusions (figure 10).

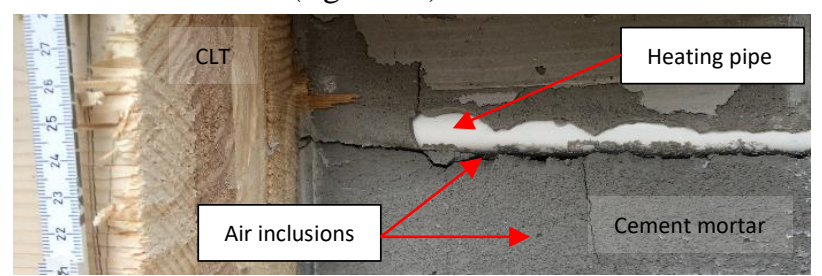

Figure 10: Dwindling of the mortar.

Without additional laboratory investigations, the measured temperature decrease of approximately $10 \mathrm{~K}$ trough the $0.1 \mathrm{~m}$ thick glue free CLT layer cannot be explained. The calculated properties of the CLT layer correspond to those of an insulation layer with a thermal conductivity of $0.04 \mathrm{~W} / \mathrm{mK}$. According to the data sheet of the wood panel, the thermal conductivity should be between $0.08 \mathrm{~W} / \mathrm{mK}$ and $0.12 \mathrm{~W} / \mathrm{mK}$. An explanation attempt is again the air inclusion, since this type of plywood panels are dowelled instead of glued over the entire surface (Figure 11).

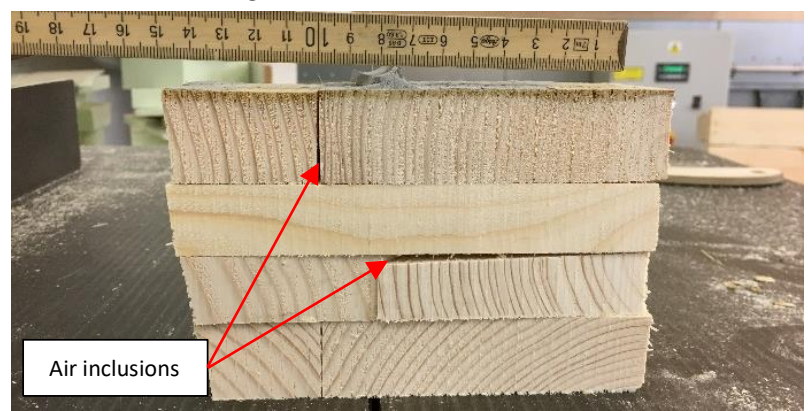

Figure 11: CLT air inclusions.

In order to specify the material parameters with higher accuracy, additional measurements need to be conducted for further research.

Figure 12 displays the temperature band of the IDA ICE simulation (red: maximum temperature, blue: minimum temperature) in comparison with the measured room temperature (the black dotted line). Due to missing measurement data of the room temperature from the adjacent flat above the measured room, several simulation runs with different adjacent flat temperatures, between $15^{\circ} \mathrm{C}$ and $26^{\circ} \mathrm{C}$, are conducted. The average room temperature difference between measurements and simulations of the tested bedroom, during the 20-day simulation period, is approximately $0.1 \mathrm{~K}$. Additionally, there is a slight deviation of the room temperature of approximately $0.2 \mathrm{~K}$ between measurements and simulation over the whole simulation period. During natural ventilation times, the simulated room temperature drops up to $2.5 \mathrm{~K}$ below the measured results, which is caused by multiple reasons: the data logging interval of

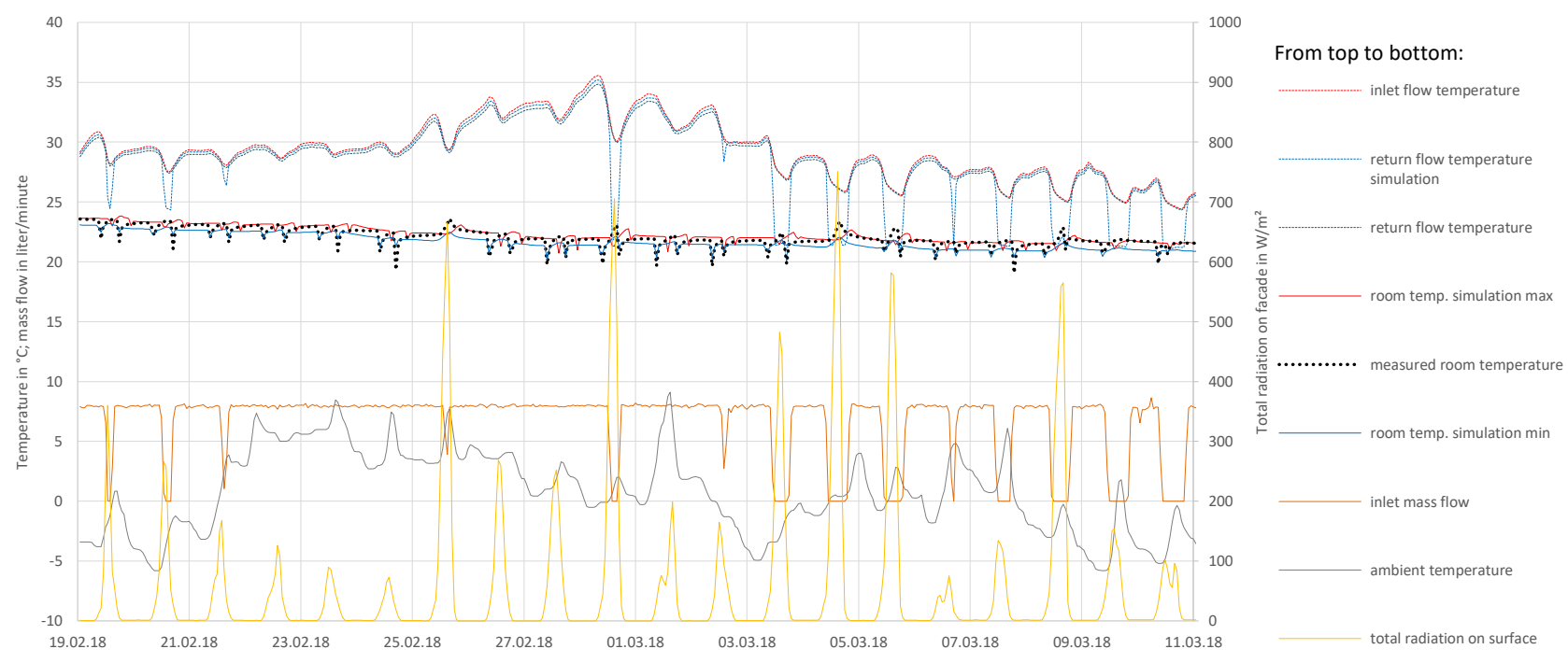

Figure 12: Bandwidth of room temperature. 
one minute, the slight inertial behavior of the temperature sensor and the close distance between the inside wall and the room temperature sensor. Nevertheless, results show an agreeable deviation between simulated and measured room temperature.

Besides the described deviations in temperature, the return flow temperature of the radiant heating circuit differs between simulation and measurement. During the simulation period of three weeks, the simulated return flow temperature from the radiant heating device is averagely $0.54 \mathrm{~K}$ above the measured return flow temperature. Comparing the data from the heat quantity meter with the simulation results shows that the calculated value for the heating energy demand $(12.3 \mathrm{kWh})$ is $50 \%$ of the measured value $(24.5 \mathrm{kWh})$ which is confirmed through additional simulations in WUFI Pro 6.2.

The comparison reveals that both simulation methods are resulting in slightly higher temperatures through the whole wall cross-section, but the differences are not high enough to account for the gap in heating energy demand. Implementing the measured heating energy demand within the simulation would lead to temperatures above the measured values. The reason for those discrepancies can be traced back to a measurement failure of the heat quantity meter at low mass flows (8 liters/minute) compared to the given nominal flow (25 liter/minute).

\section{Minimum inlet flow temperature}

In order to determine the necessary inlet flow temperature of the façade heating circuits to ensure a room temperature of $26^{\circ} \mathrm{C}$, a modified simulation model of the previous described validation model is created. The modified boundary conditions are set accordingly:

- Climate: ASHRAE IWEC 2 Salzburg Airport

- Adjacent rooms are calculated adiabatically

- Basement temperature: $10^{\circ} \mathrm{C}$ const.

- Inlet mass flow: constant 5 liters/minute

- Air change rate: $0.15 \mathrm{~h}^{-1} ; 0.3 \mathrm{~h}^{-1}$ between 08:00-09:00 and 18:00-19:00 through mechanical ventilation

Beside the implementation of a synthetic climate file and the assumption of adiabatic conditions of the adjacent zones, another major difference between the validation model and the modified model is the limitation of the inlet mass flow. A value of five liters per minute is chosen, which represents a typical maximal value for radiant heating flow limiter. The ventilation is ensured by an exhaust fan. This modification is necessary in order to make the results suitable for the planned refurbishment approach, which includes an exhaust fan inside the sanitary rooms and inlet air ducts above the refurbished windows. During the simulation period of two months, between January and February 2018, a parametric run with Genopt 3.1.1 was conducted. Figure 13 displays the linear relationship between the minimum room temperature over the whole simulation period and the inlet flow temperature. As a result, an inlet flow temperature of $42^{\circ} \mathrm{C}$ is suitable to ensure possible room temperatures of $26^{\circ} \mathrm{C}$ at any time of the year.

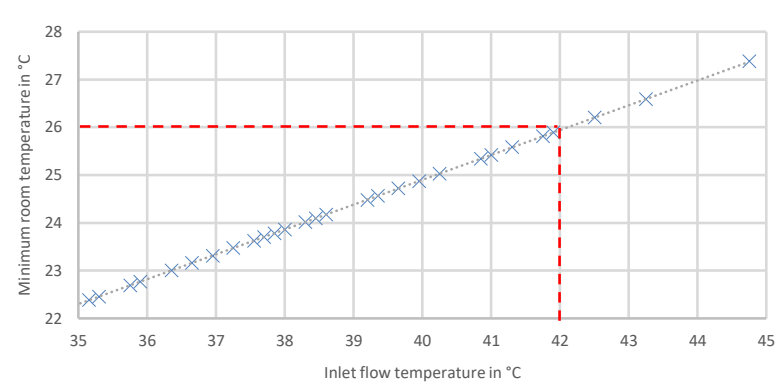

Figure 13: Parametric run room-/flow-temperature.

\section{Control strategy - pulsing}

The first of the two considered control strategies is the regulation of the room temperature by means of a room thermostat and a pulsing (on/off) control of the inlet mass flow. Relevant boundary conditions are set accordingly:

- Climate: ASHRAE IWEC 2 Salzburg Airport

- Adjacent rooms are calculated adiabatically

- Basement temperature: $\quad 10^{\circ} \mathrm{C}$ const.

- Inlet flow temperature: $\quad 42^{\circ} \mathrm{C}$ const.

- Inlet mass flow: pulsing (on/off) 5 liters/minute

- Air change rate: $0.15 \mathrm{~h}^{-1} ; 0.3 \mathrm{~h}^{-1}$ between 08:00-09:00 and 18:00-19:00 through mechanical ventilation

- Target room temperature: $\quad 22{ }^{\circ} \mathrm{C}$

- Dead-band of thermostat: $\quad \pm 1 \mathrm{~K}$

Figure 14 displays the simulated results for the month of January. Due to the pulsing control, the set dead-band of $\pm 1 \mathrm{~K}$ and the inertial behavior caused by the high thermal mass, the room temperature exceeds the desired temperature of $22^{\circ} \mathrm{C}$ by $2 \mathrm{~K}$. A similar phenomenon can be detected during the switching phase of the controller from off to on. This overheating leads to a less frequent opening behavior of the inlet mass flow valve ( every 1.5 weeks). Over the whole year, $431 \mathrm{kWh}\left(40.6 \mathrm{kWh} / \mathrm{m}^{2} \mathrm{a}\right)$ heating energy is used for conditioning of the simulated room.

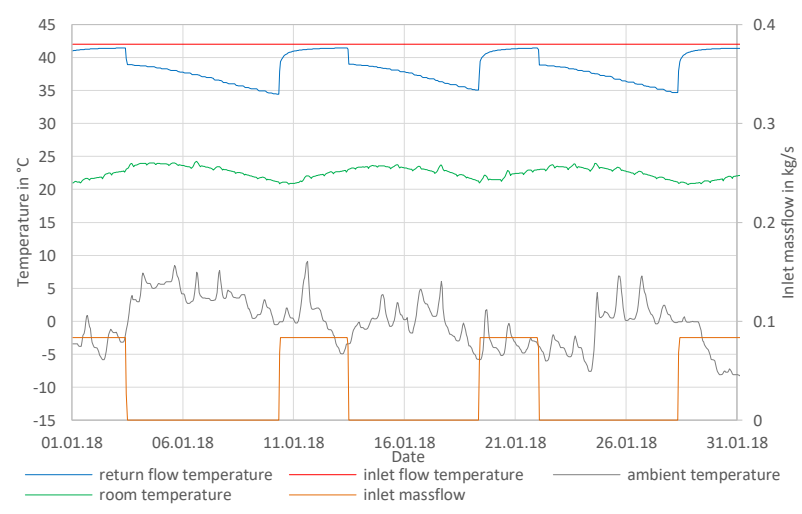

Figure 14: Pulsing control-January.

Due to the location of the heating circuit on the outside of the existing wall structure, the simulation shows that approximately $24 \%$ of the energy flows are directed towards the outside environment throughout the whole heating season of the year.

\section{Control strategy - sliding}

The second considered control strategy is the regulation of the room temperature by means of a PI controller and 
a sliding control of the inlet mass flow. Relevant boundary conditions are set accordingly:

- Climate: ASHRAE IWEC 2 Salzburg Airport

- Adjacent rooms are calculated adiabatically

- Basement temperature: $\quad 10{ }^{\circ} \mathrm{C}$ const

- Inlet flow temperature: $\quad 42^{\circ} \mathrm{C}$ const.

- Inlet mass flow: sliding $0-5$ liters/minute

- Air change rate: $0.15 \mathrm{~h}^{-1} ; 0.3 \mathrm{~h}^{-1}$ between 08:00-09:00 and 18:00-19:00 through mechanical ventilation

- Target room temperature: $22{ }^{\circ} \mathrm{C}$

- PI-Controller:

- Gain parameter: 0.3

- Tracking time: 15 minutes

- Integration time: 2.5 hours

Figure 15 gives an overview of the simulated results for the month of January. The PI controller is configured according to recommendations of Schrowang (Recknagel, 2014) for room temperature driven heating controls. Due to the sliding control of the inlet mass flow between zero and five liters per minute and the inertial behavior of the wall structure, the room temperature exceeds the desired temperature of $22{ }^{\circ} \mathrm{C}$ by $2 \mathrm{~K}$, which is similar to the results of the pulsing control strategy. Nevertheless, the room temperature inside the simulated zone is more stable compared to a pulsing control. In addition, a more frequent opening of the inlet flow control valve can be observed. Over the whole year, $429 \mathrm{kWh}\left(40.4 \mathrm{kWh} / \mathrm{m}^{2} \mathrm{a}\right)$ of heating energy is needed for conditioning the simulated room. Due to the location of the heating circuit on the outside of the existing wall structure, approximately $24 \%$ of the energy are directed to the outside environment throughout the whole heating season of the year. Both results concerning the heating energy demand and the energy loss to the outside environment show very little discrepancies between the two control strategies.

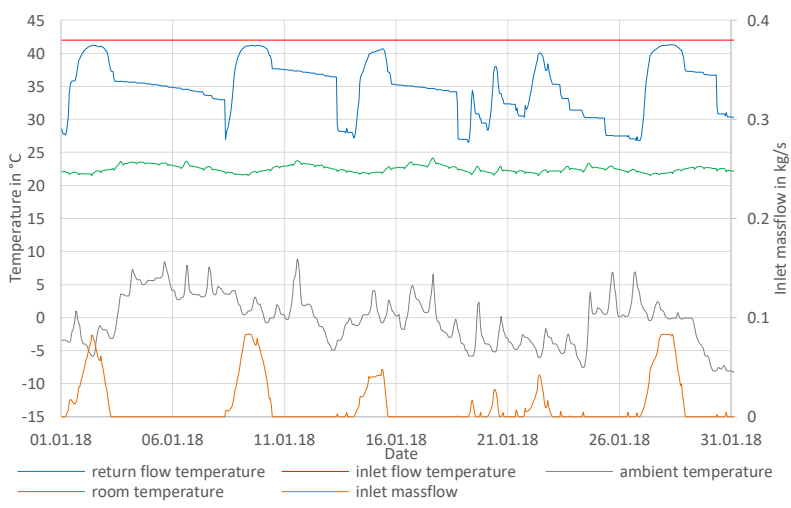

Figure 15: Sliding control-January.

\section{Conclusion}

A validated model of the prefabricated multifunctional radiant heating façade element in interaction with the existing wall structure of the building is achieved with an acceptable accuracy. The average difference between measurement and simulation is $0.1 \mathrm{~K}$, increasing up to $2.5 \mathrm{~K}$ during ventilation times through window openings. These differences can be caused by a lack of measurement data due to limited financial resources e.g.: temperature from the adjacent flat above the measurement room, ambient wind speed, air change rate, door openings and measurement accuracy of sensors.

The temperature gradient from the measurements corresponds with the calculations by adopting the following modifications of material properties:

- The existing brickwork layer is likely to be a heavy, highly thermally conductive brickwork. It seems appropriate to set the average thermal conductivity of the layer to a value $0.83 \mathrm{~W} / \mathrm{mK}$ and the mass density at $1800 \mathrm{~kg} / \mathrm{m}^{3}$.

- The surface resistance to heat flow on the inside of the wall is rather low with a value of $0.07 \mathrm{~W} / \mathrm{m}^{2} \mathrm{~K}$.

- The average thermal conductivity of the thermally activated cement mortar layer of $0.5 \mathrm{~W} / \mathrm{mK}$ is unexpectedly low, which can be contributed to air inclusions caused by the dwindling behavior.

- The measured high temperature drop in the CLT layer cannot be explained in a plausible way without additional laboratory measurements. According to the data sheet of the wood panel, the thermal conductivity should be between $0.08 \mathrm{~W} / \mathrm{mK}$ and $0.12 \mathrm{~W} / \mathrm{mK}$. The calculated properties of the CLT layer correspond to those of an insulation layer with a thermal conductivity of $0.04 \mathrm{~W} / \mathrm{mK}$

Due to regulations of the building operator, the tenants need to have the possibility to adjust the room temperature to a maximum of $26^{\circ} \mathrm{C}$. The results of the conducted parameter study within GenOpt 3.1.1 show that an inlet flow temperature of $42{ }^{\circ} \mathrm{C}$ is necessary to ensure the required room temperature of $26^{\circ} \mathrm{C}$, under the prerequisite that the inlet mass flow is limited to 5 liters per minute for each heating circuit analogous to industrial standard values.

The room temperature is a relevant parameter for the characterization of the thermal comfort and therefore for the satisfaction of the tenants. With a set room temperature of $22^{\circ} \mathrm{C}$, both for sliding and pulse control, a whisker plot (shown in figure 16), created within IBM SPSS Statistics 24, is conducted.

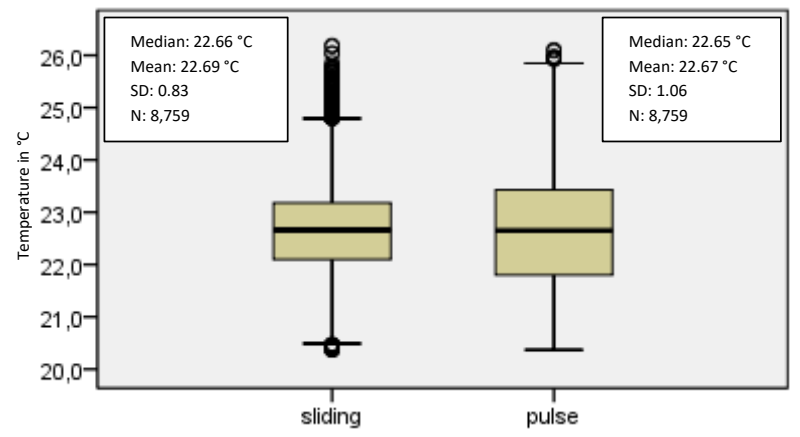

Figure 16: Room temperature; pulse and sliding control.

The lower bottom of the box indicates the lower quartile and therefore the position of the $25 \%$ lowest values. The line within the box shows the location of the median and the end of the box the upper quartile. The rings above the upper whisker represent moderate outliers. With a value of $22.67{ }^{\circ} \mathrm{C}$, the median of the room temperature with pulse control is almost identical to the median of sliding 
control with $22.69^{\circ} \mathrm{C}$. The difference between the two control strategies is shown by a comparison of the standard deviation. With a value of 0.83 the standard deviation for sliding control is $28 \%$ lower than the standard deviation for pulse control. In order to ensure a homogenous temperature distribution, the lower bandwidth of the sliding control shows a clear advantage under the presumed parameters over the pulse control strategy and is therefore suggested for further planning.

\section{Outlook}

The ongoing refurbishment of the entire building is expected to be completed in spring 2019. The sliding control strategy of the heating system will be set analogous to the results of the thermal building simulation. With the help of additional measurements and accompanying simulation of the entire building, the control strategy will be subsequently optimized and tested during ongoing operation, especially during the heating season of 2019/2020. With simulation results of the whole building, a comparison between the unrefurbished building in terms of heating energy demand will be conducted. The CLT layer will be replaced by a standard glued timber layer. Therefore, modifications in the existing simulation model are necessary and additional laboratory measurement of the CLT layer used in the prototype in order to specify the material properties can be avoided, but should be conducted for the new glued timber layer. For the further validation process, it is necessary to install additional sensors (e.g. wind speed measurement, surface temperatures etc.) Due to the incomparable way of refurbishing, no economic efficiency calculation was conducted. Future research could deal with an in detail economic analysis.

\section{Acknowledgement}

The presented results were obtained within the research project "Alpine Building Centre" (www.alpinesbauen.at), under the direction of Thomas Reiter, who made this project possible through his commitment. The data basis for this paper was obtained from the research project "Wohnen findet Stadt - Sondierung Hallein", commissioned and funded by the "Klima- und Energiefonds" under the authority of the Austrian Federal Ministry for Transport, Innovation and Technology (BMVIT) and the research project "Salzburger Multifunktionsfassade", commissioned and funded by the county of Salzburg. Project partners: Architekt Paul Schweizer, Salzburg University of Applied Sciences, City of Hallein, RSA iSpace Forschungsgesellschaft $\mathrm{mbH}$, Planum Fallast Tischler \& Partner GmbH, Innova Holz $\mathrm{GmbH}$, VELOX Werk GmbH, Isocell GmbH, Schaber Anton Installationen, Gebäude- und Regeltechnik GmbH, KEKELIT Kunststoffwerk GmbH, Raumklima Planungsgesellschaft $\mathrm{GmbH}$

\section{References}

Bindra, S. and Scanlon, X. (2010). UNEP annual report. 2009. Seizing the green opportunity. Nairobi: United Nations Environment Programme (UNEP). Available at: http://wedocs.unep.org [accessed: 8 Jan 2019]
Birchall S., Gustafsson, M., Wallis, I., Dipasquale, C., Bellini, A., Fedrizzi, R. (2016). Survey and simulation of energy use in the European building stock. Available at: http://www.diva-portal.org [accessed: 8 Jan 2019]

EN 13465. (2004). Ventilation for buildings. Calculation methods for the determination of air flow rates in dwellings.

ÖNORM B 8110-7. (2013) Wärmeschutz im Hochbau Teil 7: Tabellierte wärmeschutztechnische Bemessungswerte.

ÖNORM EN ISO 6946. (2018) Wärmedurchlasswiderstand und WärmedurchgangskoeffizientBerechnungsverfahren

Recknagel, H., Sprenger, E., Schramek, E.R. (2014). Taschenbuch für Heizung und Klimatechnik. 76. Auflage, Oldenbour Industrieverlag $\mathrm{GmbH}$, München, 449.

Schmidt, C., Luther, G., Altgeld, H., Maas, S., Groß, B., Scholzen, F. (2017). „Außenliegende Wandtemperaierung“ - LowEx-Anwendung zur Temperierung von Bestandsgebäuden und thermischen Aktivierung der Bestandswand: theoretische Grundlagen und Kennwerte. Bauphysik 39 (2017), Heft 4

Statistics AUSTRIA. (2016). Gebäude 2011 nach überwiegender Gebäudeeigenschaft, Errichtungsjahr und Bundesland. Available at: https://www.statistik.at/web_de/statistiken [accessed: 8 Jan 2019].

Todorovic, R., Banjac, M., Gojak, M. (2015). Theoretical and experimental study of heat transfer in wall heating panels. Energy and Buildings 98 (2015) 66-73 